\title{
Experiences with using of loading tests and the "Design assisted by testing" method for the determination and verification of structural members and details
}

\author{
Michal Štrba, Marcela Karmazínová, Pavla Bukovská \\ Received: August 6, 2020. Revised: December 27, 2020. Accepted: January 9, 2021. Published: January 14, 2021.
}

\begin{abstract}
This paper describes experiences with use of different types of experiments (i.e. loading tests) as well as with use of socalled "Design assisted by testing" method given in the standard "Eurocode 1". Both these mentioned ways are useful in case of a determination and verification of important design parameters, material properties and load-carrying capacities (in case of different types of stresses, used materials or geometric configurations of designed constructions or their elements and details).

In this area, during recent years, large number of miscellaneous loading tests have been performed at the authors' workplace. Therefore, all presented information and all described experiment results in this article are directly based on solved experimental (and theoretical) research programs carried out at Institute of Metal and Timber Structures at the Faculty of Civil Engineering at Brno University of Technology in cooperation with research institutes and companies in the Czech Republic.

Most of all research projects were focused on the load-carrying capacity determination as well as on the knowledge about an actual behaviour and failure mechanisms of steel and steel-concrete structural members and details (recently of members made of FRP or GFRP composite, too), usually in case of verification of either existing or newly designed building or bridge structures.
\end{abstract}

Keywords - Design assisted by testing, design characteristics, experiments, load-carrying capacity determination, loading tests, steel constructions, parameters verification.

\section{INTRODUCTION}

$\mathrm{W}$ HILE verifying the existing construction elements in the case of different design parameters (different material characteristics, geometry, load configuration, etc.), it is very

This paper has been worked out under the project No. FAST-S-20-6400 "The analysis, experimental verification and possibilities of the interaction of materials effective utilization in case of composite construction members", which is a "specific research" project of the Brno University of Technology, supported by Ministry of Education, Youth and Sports of the Czech Republic.

M. Štrba, Faculty of Civil Engineering, Brno University of Technology, Veveři St. 331/95, 602 00, Brno, Czech Republic, (phone: 420-54114-7305; e-mail: strba.m@fce.vutbr.cz).

M. Karmazínová, Faculty of Civil Engineering, Brno University of Technology, Veveří St. 331/95, 602 00, Brno, Czech Republic, (e-mail: karmazinova.m@fce.vutbr.cz).

P. Bukovská, Faculty of Civil Engineering, Brno University of Technology, Veveři St. 331/95, 602 00, Brno, Czech Republic, (e-mail: bukovska.p@fce.vutbr.cz). often necessary to realize various loading tests. Then, the main reason for using those experiments may be the lack of relevant data for these members (or constructions) in case of expected specific kind of stresses, material characteristics, etc.

Usually, some standards with special rules for a geometry of specimens, for load characteristics (specific loading speed, support configurations, deflection limits, etc.) as well as for failure mechanisms are available for these loading tests.

Then, it is necessary to follow the given standard rules for the experiments and next use probability and statistics methods to determine load-carrying capacities, resistances or other important parameters with expected level of safety (assuming a certain safety factor). Each type of construction has usually its own rules or standards (except some newly designed construction made of progressive materials which are still under research (for example the previously mentioned FRP and GFRP composite members used in civil engineering and building constructions).

On the contrary, while designing a new type of structural member, very often no standards nor rules for the loading tests are available. Therefore, it is necessary to design a new configuration of the loading tests together with all the rules for specimens as well as for loading test arrangements. Also, in this case, it is very convenient to use the mentioned "Design assisted by testing" method given in Annex " $D$ " of the European standard Eurocode EN 1990, Basis of Structural Design [1] [2].

With this method it is possible to determine characteristic or design values (of load-carrying capacities, resistances, etc.), directly according to obtained experiment data in dependence on a number of performed experiments (i.e. of the number of tested specimens).

For this method it is also important if at least some material characteristics are known of the newly designed members (for example, if it is possible to find coefficients of variation of used material, etc.).

Therefore, this article brings information about several selected examples of both mentioned ways (i.e. loading tests as well as Design assisted by testing method), which are, certainly, very often combined together in case of a research project solution to get an efficient and economic design. 


\section{Methods OF THE DESIGN ASSISTED BY TESTING}

A principle approach of the Design assisted by testing method and its application can be taken as a very useful way for a determination of characteristic or design values of selected material properties as well as for a determination of design resistances of structural bearing members.

Several types of (loading) test/experiments could be taken into account in case of a utilization of the Design assisted by testing method.

In general, after processing by statistical methods, results of following four types of tests may be directly used for a determination of needed values, which are possible to use for a design:

a) Experiments for direct establishing of the ultimate resistance or serviceability properties of constructions or structural members while loading conditions are given. They can be used, for example, to determine a response of a structure to load variability (e.g. fatigue loads or impact loads can be considered).

b) Loading tests for obtaining of specific material properties with the help of specified testing procedures (for example, a laboratory or an in-situ testing of a subsoil, or the testing of new materials can be mentioned).

c) Tests designed for reducing of possible uncertainties in load parameters or in load effect models. For instance, by wind tunnel testing, or by testing to identify and specify actions caused by waves).

d) Loading tests for reducing of uncertainties in parameters used in selected resistance models. As an example, tests of structural members or assemblies of structural members can be mentioned (e.g. floor or roof structures).

Then, with the help of next three types of loading tests some other properties can be established:

e) Control tests for checking of an identity or quality of any products or of a consistency of production characteristics. For example, tests of concrete cubes or a testing of cables for bridges.

f) Tests carried out during building construction in order to obtain information needed for construction phases (for instance, testing of pile resistance or testing of cable forces during bridge construction).

g) Checking of an actual behaviour of structures or structural members after construction is completed. For example, tests for obtaining of elastic deflections, frequencies of vibration or damping values can be mentioned.

The annex D itself [1] is used primarily in case of described types a) - d), where design values to be used should be derived from the test results by applying appropriate statistical techniques.

However, some special methods could be needed in order to evaluate test results in case of the test type c).
For a determination of a design value of material properties, model parameters or resistances one of following methods should be used:

(I) First, characteristic values $X_{\mathrm{k}}$ are being determined. Then, these values have to be divided by partial factors $\gamma_{m}$ and by explicit conversion factors $\eta_{d}$ (if needed).

(ii) Design values are being determined directly considering a conversion of test results (explicitly or implicitly) and considering a required reliability, too.

Generally, the method a) is preferred with applying partial factors according to the appropriate Eurocode. However, with the method a) also a scatter of test data together with statistical uncertainty (based on the number of tests) have to be provided.

Procedures for both approaches (a determination of a model resistance and a determination of a single material property) are very comprehensively described in the „Annex D” [1] [2], as well as in selected papers focused on the Design assisted by testing philosophy and application, for example, see [3]-[8]. Some more information can be also found in standards [9] [10]. Thus, only some basic procedures and formulas are described below in next two sub-chapters.

\section{A. Determination of a single material property}

For a determination process of design values in case of one single property $X$ (e.g. a strength of the product or a structural member resistance), following procedures are defined, where given fractile factors $k_{\mathrm{n}}$ and $k_{\mathrm{d}, \mathrm{n}}$ are used from Table 1 and Table 2 (see below). The fractile factors as well as the formulas (1) to (5) below are based on few assumptions:

- all the relevant variables follow either a normal or a lognormal distribution,

- the mean value is not primarily known,

- where no prior knowledge about the variation coefficient is available, the case " $V_{X}$ unknown" should be taken,

- where a full knowledge about the variation coefficient is available, the case " $V_{X}$ known" should be taken.

Then, respecting a total number of tests together with statistical distribution of selected material property and its variability (described by its variation coefficient), both, characteristic as well as design values of a selected material property can be determined according the following formulas.

In case of the method defined as (i) (see above), where the procedure is based on a characteristic value of property $X_{\mathrm{k}}$ (usually $5 \%$ characteristic value), the design value $X_{\mathrm{d}}$ can be taken (based on an assumption of normal distribution) as:

$X_{\mathrm{d}}=\eta_{\mathrm{d}} \frac{X_{\mathrm{k}(\mathrm{n})}}{\gamma_{m}}=\frac{\eta_{\mathrm{d}}}{\gamma_{m}} m_{X}\left\{1-k_{\mathrm{n}} \cdot V_{X}\right\}$,

where $\eta_{d}$ is the design value of the conversion factor and $m_{X}$ is the mean of the $\mathrm{n}$ sample results. Appropriate partial factors $\gamma_{m}$ have to be chosen according to the way of application of test results. Other values have been already defined above. Fractile factors $k_{n}$ according to test number $n$ are given in Table 1 . 
Assuming the variation coefficient $V_{X}$ as unknown from prior knowledge, its value has to be estimated from the test sample.

Next, if a log-normal distribution is assumed for the material property, the design value $X_{\mathrm{d}}$ can be taken according the next formula:

$X_{\mathrm{d}}=\frac{\eta_{\mathrm{d}}}{\gamma_{m}} \exp \left[m_{y}-k_{\mathrm{n}} \cdot s_{y}\right]$

$m_{y}=\frac{1}{n} \sum \ln \left(x_{i}\right)$,

where $m_{y}$ is the mean and $s_{y}$ is the standard deviation, which has to be determined differently in case of $V_{X}$ known as well as $V_{X}$ unknown according given forms in [1].

Table 1 Values of $k_{\mathrm{n}}$ according to test number $n$ [1]

\begin{tabular}{|cc|c|c|c|c|c|c|}
\hline \multicolumn{7}{|c|}{ Fractile factors $k_{\mathrm{n}}$ for $5 \%$ characteristic value } \\
\hline & $n$ & 2 & 3 & 4 & 5 & 6 & 7 \\
\hline$V_{x}$ & known & 2.010 & 1.890 & 1.830 & 1.800 & 1.770 & 1.755 \\
\hline$V_{x}$ & unkonwn & - & 3.370 & 2.630 & 2.330 & 2.180 & 2.090 \\
\hline & $n$ & 8 & 9 & 10 & 11 & 12 & 13 \\
\hline$V_{x}$ & known & 1.740 & 1.730 & 1.720 & 1.716 & 1.712 & 1.708 \\
\hline$V_{x}$ & unkonwn & 2.000 & 1.960 & 1.920 & 1.904 & 1.888 & 1.872 \\
\hline & $n$ & 14 & 15 & 16 & 17 & 18 & 19 \\
\hline$V_{x}$ & known & 1.704 & 1.700 & 1.696 & 1.692 & 1.688 & 1.684 \\
\hline$V_{x}$ & unkonwn & 1.856 & 1.840 & 1.824 & 1.808 & 1.792 & 1.776 \\
\hline & $n$ & 20 & 21 & 22 & 23 & 24 & 25 \\
\hline$V_{x}$ & known & 1.680 & 1.679 & 1.678 & 1.677 & 1.676 & 1.675 \\
\hline$V_{x}$ & unkonwn & 1.760 & 1.757 & 1.754 & 1.751 & 1.748 & 1.745 \\
\hline & $n$ & 26 & 27 & 28 & 29 & 30 & $\infty$ \\
\hline$V_{x}$ & known & 1.674 & 1.673 & 1.672 & 1.671 & 1.670 & 1.640 \\
\hline$V_{x}$ & unkonwn & 1.742 & 1.739 & 1.736 & 1.733 & 1.730 & 1.640 \\
\hline
\end{tabular}

Table 2 Values of $k_{\mathrm{d}, \mathrm{n}}$ according to test number $n$ [1]

\begin{tabular}{|cc|c|c|c|c|c|c|}
\hline \multicolumn{7}{|c|}{ Fractile factors $k_{\mathrm{d}, \mathrm{n}}$ for the ULS design value } \\
\hline & $n$ & 2 & 3 & 4 & 5 & 6 & 7 \\
\hline$V_{x}$ & known & 3.770 & 3.560 & 3.440 & 3.370 & 3.330 & 3.300 \\
\hline$V_{x}$ & unkonwn & - & - & 11.40 & 7.850 & 6.360 & 5.715 \\
\hline & $n$ & 8 & 9 & 10 & 11 & 12 & 13 \\
\hline$V_{x}$ & known & 3.270 & 3.250 & 3.230 & 3.223 & 3.216 & 3.209 \\
\hline$V_{x}$ & unkonwn & 5.070 & 4.790 & 4.510 & 4.423 & 4.336 & 4.249 \\
\hline & $n$ & 14 & 15 & 16 & 17 & 18 & 19 \\
\hline$V_{x}$ & known & 3.202 & 3.195 & 3.188 & 3.181 & 3.174 & 3.167 \\
\hline$V_{x}$ & unkonwn & 4.162 & 4.075 & 3.988 & 3.901 & 3.814 & 3.727 \\
\hline & $n$ & 20 & 21 & 22 & 23 & 24 & 25 \\
\hline$V_{x}$ & known & 3.160 & 3.157 & 3.154 & 3.151 & 3.148 & 3.145 \\
\hline$V_{x}$ & unkonwn & 3.640 & 3.620 & 3.600 & 3.580 & 3.560 & 3.540 \\
\hline \multicolumn{2}{|c|}{$n$} & 26 & 27 & 28 & 29 & 30 & $\infty$ \\
\hline$V_{x}$ & known & 3.142 & 3.139 & 3.136 & 3.133 & 3.130 & 3.040 \\
\hline$V_{x}$ & unkonwn & 3.520 & 3.500 & 3.480 & 3.460 & 3.440 & 3.040 \\
\hline
\end{tabular}

In case of the direct assessment of the design value as it was defined in method marked as (ii) on previous page, the design value $X_{\mathrm{d}}$ for the material property $X$ (assuming the normal distribution) should be found using this formula:

$X_{\mathrm{d}}=\eta_{\mathrm{d}} \cdot m_{X}\left\{1-k_{\mathrm{d}, \mathrm{n}} \cdot V_{X}\right\}$,

where the conversion factor $\eta_{\mathrm{d}}$ should consider all possible uncertainties not covered by the tests themselves. Then, the values of factors $k_{\mathrm{d}, \mathrm{n}}$ can be found in Table 2 .

Finally, with an assumption of log-normal distribution of the property, the expression of the formula (4) for the design value becomes:

$X_{\mathrm{d}}=\eta_{\mathrm{d}} \cdot \exp \left(m_{y}-k_{\mathrm{d}, \mathrm{n}} \cdot s_{y}\right)$

The procedure with use of " $V_{X}$ known" is recommended for the conservative estimation of a variation coefficient. On the contrary, if the " $V_{X}$ unknown" procedure is used, then no value less than 0.1 should be considered. Then, all test results should be elaborated by appropriate statistical methods, for example according to [11].

A simplified scheme of whole determination process with the help of Design assisted by testing in case of some single property is shown in Fig. 1.

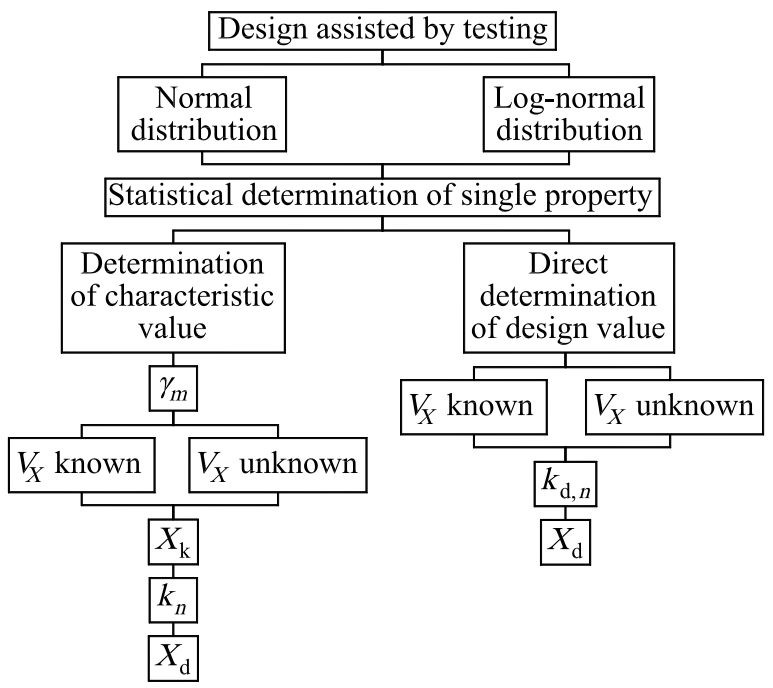

Fig. 1 scheme of the Design assisted by testing method in case of the statistical determination of a single property

Generally, the use of a log-normal distribution for a variable has the advantage that negative values cannot occur (which would be very inappropriate for geometrical and resistance variables).

\section{B. Determination of resistance models}

As mentioned above, except described procedures for the statistical evaluation of one single property, Design assisted by testing method gives also the way for the determination of resistance models and for a derivation of design values from tests defined as type d) on previous page. 
For this purpose, two standard evaluation procedures marked Method (a) and Method (b) are distinguished in the Annex D of the standard [1]. Both methods are defined through seven discrete steps, where first six of them are the same for both methods and a difference is only in the very last one.

The first evaluation procedure for a characteristic value estimation, Method (a), is based on several presumptions (e.g., resistance functions are functions of a number of independent variables; a sufficient number of test results is available, relevant properties have to be measured, no correlation exist between the variables, which follow either a normal or a lognormal distribution).

As mentioned above, seven particular steps (Step 1 - Step 7) are defined for Method (a).

First, in Step 1, a design model for the theoretical resistance $r_{t}$ is developed, based on the resistance function $g_{r t}(\underline{X})$, which covers basic variables $\left(X_{1}, X_{2} \ldots\right)$ that could affect the resistance at the relevant limit state:

$r_{t}=g_{r t}(\underline{X})$.

Then, Step 2 brings, in principle, a comparison of theoretical values of a resistance $r_{t i}$ of individual specimens, which are obtained by substituting of measured properties into the chosen resistance function and experimental resistances $r_{e i}$ obtained from the tests, see Fig. 2.

If, both, values of a theoretical resistance function as well as values of a function obtained experimentally, would be the same, then all the values would lie on the line with a slope of $b=1.0$ (i.e. $\theta=45^{\circ}$ ). In this purely theoretical situation, the relationship between both resistance functions could be written as follows:

$r_{t}\left(\underline{X}_{\mathrm{m}}\right)=g_{r t}\left(\underline{X}_{\mathrm{m}}\right)$

However, in practice, some scatter of all the obtained values would occur for sure, as visible on the illustration graph on the Fig. 2. Therefore, the value of a correction factor $b \neq 1.0$ should be determined.

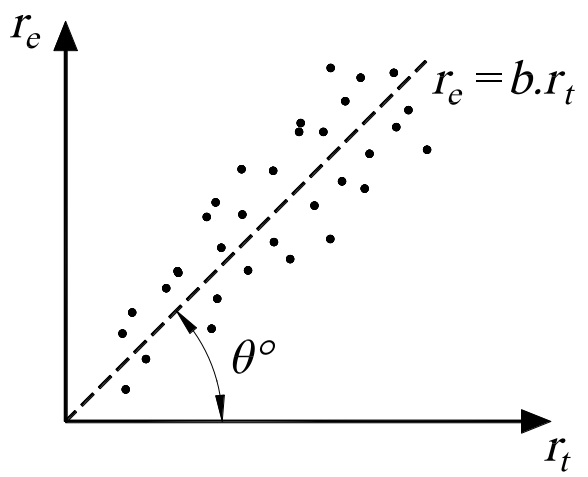

Fig. 2 illustration of a possible relationship between theoretical and experimental values of $r_{e}$ and $r_{t}$

So that, Step 3 represents an estimation of the mean value of the correction factor $b$. In order to achieve this objective, a mean value $r_{\mathrm{m}}$ of a theoretical resistance function (based on mean values $\underline{X}_{\mathrm{m}}$ of the basic variables) can be calculated according this form:

$r_{\mathrm{m}}=b \cdot r_{t}\left(\underline{X}_{\mathrm{m}}\right) \cdot \delta=b \cdot g_{r t}\left(\underline{X}_{\mathrm{m}}\right) \cdot \delta$,

where for the best estimation of the slope $b$ the "least squares" method can be used as follows:

$b=\frac{\sum r_{e} \cdot r_{t}}{\sum r_{t}^{2}}$.

In the next Step 4, a coefficient of variation $V_{\delta}$ of all individual errors $\delta_{i}$ of each experimental value $r_{e i}$ is estimated with the help of a variance of an arithmetic mean of all error term values, i.e. $s_{\Delta}^{2}$, according:

$V_{\delta}=\sqrt{\exp \left(s_{\Delta}^{2}\right)-1}$.

Step 5 is defined as analysis, where a compatibility of the test population with values from the chosen resistance function assumptions are compared an analysed.

Step 6 is to determine the coefficients of variation of all the basic variables $V_{\mathrm{Xi}}$. Then, if the whole test population is fully representative in reality, then the variation coefficients may be determined from the test data. However, normally the coefficients of variation need to be determined on the basis of some prior knowledge.

Finally, Step 7 brings the determination of a characteristic value of the searched resistance $r_{\mathrm{k}}$ according the formula (11), where several approaches are included through its individual variables. For example, by the influence of a complexity of the resistance function (simple and more complex functions are distinguished) as well as by the influence of the number of tests (e.g., if the number of tests is more or less than 100).

$r_{\mathrm{k}}=b g_{r t}\left(\underline{X}_{\mathrm{m}}\right) \exp \left(-k_{\infty} \alpha_{\mathrm{rt}} Q_{\mathrm{rt}}-k_{\mathrm{n}} \alpha_{\delta} Q_{\delta}-0.5 Q^{2}\right)$,

where $k_{\mathrm{n}}$ value is the already mentioned characteristic fractile factor from Table $1, k_{\infty}$ is the value of $k_{\mathrm{n}}$ in case of $\mathrm{n} \rightarrow \infty$ (i.e. $\left.k_{\infty}=1.64\right), \alpha_{\delta}$ and $\alpha_{\text {rt }}$ are weighting factors for helping values $Q_{\delta}$ and $Q_{\mathrm{rt}}$. The solution for all the variables in case of mentioned different approaches is very complex and can be found in [1] [2]. Here, only the general resulting equation is given in (11). A simplified equation in case of large number of tests can be also found in [1].

The second evaluation procedure, Method (b), brings direct determination of the design value of the resistance $r_{\mathrm{d}}$. As it was mentioned above, in this method, Step 1 to Step 6 are exactly the same as in Method (a).

Then, in Step 7, the characteristic fractile factor $k_{\mathrm{n}}$ is replaced by the design fractile factor $k_{\mathrm{d}, \mathrm{n}}$ from Table 2 for the case " $V_{X}$ unknown". The final general formula is given as:

$r_{\mathrm{d}}=b g_{r t}\left(\underline{X}_{\mathrm{m}}\right) \exp \left(-k_{\mathrm{d}, \infty} \alpha_{\mathrm{rt}} Q_{\mathrm{rt}}-k_{\mathrm{d}, \mathrm{n}} \alpha_{\delta} Q_{\delta}-0.5 Q^{2}\right)$. 
In (12) the fractile factor $k_{\mathrm{d}, \infty}$ is taken as the value of $k_{\mathrm{d}, \mathrm{n}}$ in case of $\mathrm{n} \rightarrow \infty$ (i.e. $k_{\mathrm{d}, \infty}=3.04$, see Table 2). All the other values have been mentioned above while describing the Method (a).

It is obvious, that the Design assisted by testing method has a very wide range of use and application in case of structural members and details design. It can be advantageously used in combination with load tests to obtain characteristic or design values of the examined properties or resistances. The following chapter describes some examples of this use, which were done on the authors' workplace.

\section{THE USE OF LOAD TESTS THEMSELVES OR OF THEIR} COMBINATION WITH DESIGN ASSISTED BY TESTING METHOD

\section{A. Fatigue load tests of steel footbridge connections}

The use of loading tests without the additional use of the Design assisted by testing approach in case of a development of temporary footbridges for pedestrians and cyclists can be mentioned.as a first basic example in the event of the steel structure design. This testing have been carried out as one part of a research project whose main goal was to design a light temporary construction which would be easy to assemble while meeting and respecting all given normative requirements and conditions of safety and efficiency [12]-[14].

In fact, the main reason for making such a research project was the significant lack of temporary footbridges in the Czech Republic. As they can generally be used in the case of some damage caused by natural disasters, floods, etc., or also in the case of temporary site solutions and road reconstruction, it is important to have enough such structures in stock.

In the past, many of these structures were held mainly by the Ministry of Defence (e.g. the Bailey Bridge, the Heavy Bridge System, the Mabey Johnson System, etc.). However, the supplies were depleted, many structures were irreversibly damaged or destroyed. For various reasons, many of them "became" permanent bridges. Therefore, there is currently a great shortage of usable temporary footbridges.

After preliminary research, as a result of this project, two types of footbridges have been designed and developed. They have been named as "short" footbridge and "long" footbridge, respectively. Both constructions have the same assembly system, which consist of individual $3.0 \mathrm{~m}$ long units. The main difference between the two types is the cross-section configuration.

The "short" one has been designed with an open crosssection and with a span from $3.0 \mathrm{~m}$ to $18.0 \mathrm{~m}$. The "long" one has a closed cross-section with an upper bracing system and it has been developed for the span from $18.0 \mathrm{~m}$ to $36.0 \mathrm{~m}$ (see Fig. 3). Steel of class S355 is used for both types.

As mentioned, the "short" footbridge is characterized by the open cross-section (i.e. the lateral stability of the compressed upper chord is ensured by so-called "U-frame"). It consists of two main truss girders, with the axial distance $2.36 \mathrm{~m}$ and with the height of $1.39 \mathrm{~m}$. Then, the "long" footbridge has the closed cross-section, which consists of two main truss girders with the height $2.76 \mathrm{~m}$. The axial distance of the main girders is the same as in case of "short" footbridge, i.e. $2.36 \mathrm{~m}$ (this value is based on the standard requirements for the minimum distance between the railings in case of a simultaneous traffic of pedestrians and cyclists on the temporary footbridge).

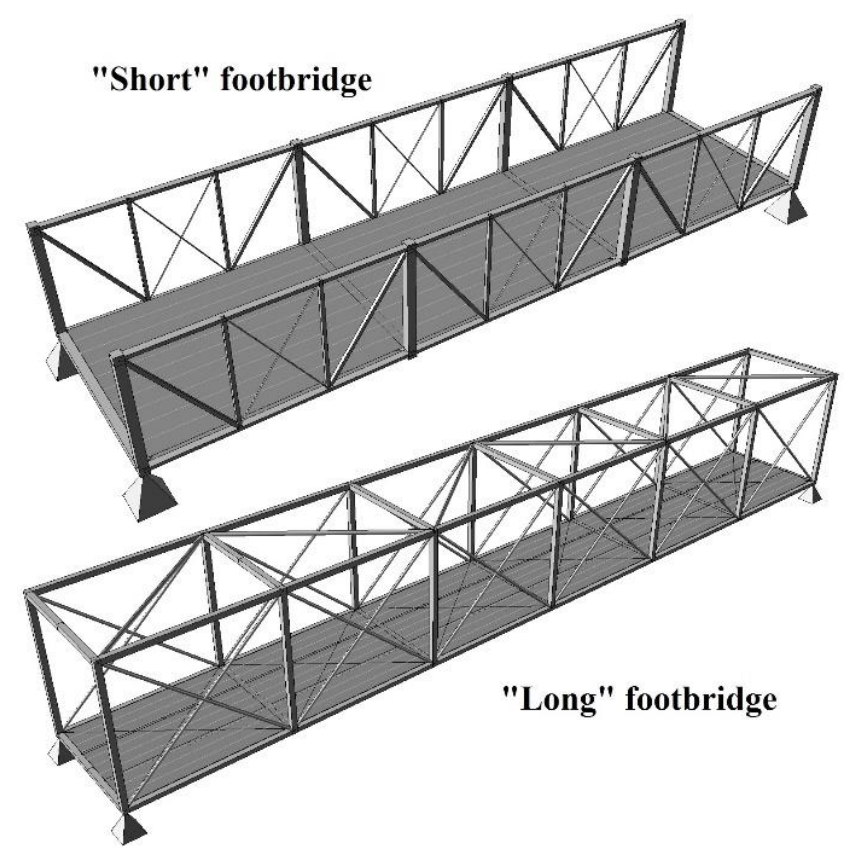

Fig. 3 scheme of both types of designed steel temporary footbridges

For more details about both footbridges see [15]-[17], where all the information about the dimensions as well as about the specific steel cross-sections can be found.

The task of developing the described steel footbridges required the design of structural joints that would be both simple and resistant to stress. Hence, for a more detailed analysis, the assembly joints of the upper and lower chords of both designed footbridges were selected. It led to a series of load tests to verify a resistance of these details, which were designed as pin connections.

Examples of all 4 mentioned construction details are shown in Fig. 4 (photographs were taken during full-scale tests, which were also part of the research, see below).

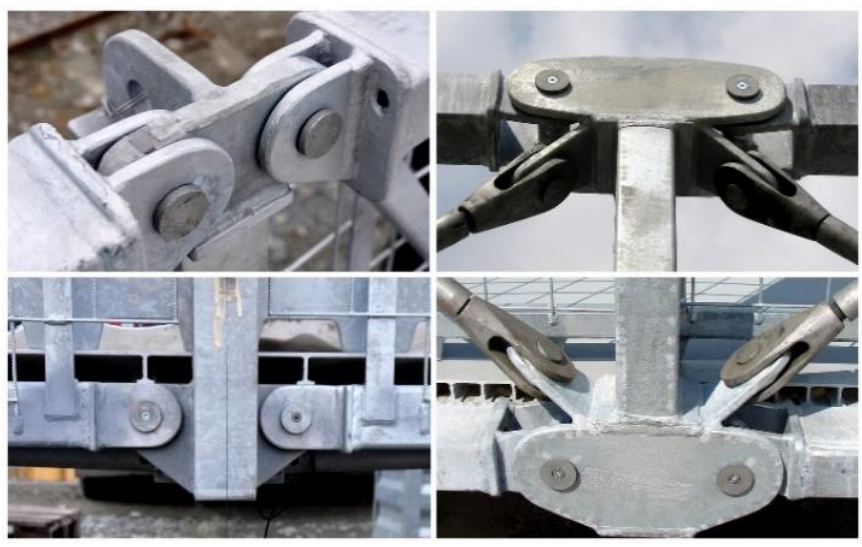

Fig. 4 real arrangement of designed assembly connections of both types of newly developed steel footbridges (the connections of the "short" footbridge are on the left) 
First, there have been realized several static tests to verify the resistance of the proposed details in the case of monotonic loading. However, in this case, most of the tests were focused on cyclic tests, because the repeated (fatigue) loading is very important and typical for all bridges, including footbridges.

Therefore, series of cyclic test were also performed to obtain the fatigue detail category for designed joints. During the experiments with cyclic forces, some specimens were tested as completed connections (including web members of the truss system of the footbridge, corresponding the actual connection arrangement). Some of them were simplified to be only chords with the connection plates and pins.

Another specific approach of the testing was, that individual components of joints were tested and after their failure (or after reaching 2 million cycles without any failure), the elements were replaced with new ones. This way, it could be finally tested 45 specimens in total.

Applying the procedure of fatigue resistance determination, the resulting categories of a fatigue detail have been obtained. In case of the weld failure the detail category was derived as $\Delta \sigma_{C}=54 \mathrm{MPa}$ (normal stress). Next, the category of a detail in case of pin failure was determined as $\Delta \tau_{C}=31 \mathrm{MPa}$ (shear stress).

Actually, the obtained resulting detail categories determined on the basis of test results were relatively low (i.e. lower than the given values in the part of Eurocode 3, which is focused on the fatigue [18].

Therefore, several subsequent structural modifications were designed (i.e. the strengthening of cross-section members as well as of connecting welds) to increase the reliability of designed connections, see [19].

Note: As a part of this research also the full-scale tests have been prepared and realized for both types of described footbridges. In case of the "short" footbridge the span of the full-scale model have been chosen $L=18.0 \mathrm{~m}$, in case of the "long" footbridge the full-scale model span have been taken as $L=36.0 \mathrm{~m}$ (i.e. in both cases the maximum possible span have been selected). The illustrations of the full-scale testing are shown in Fig. 5, where it can be also visible how the load was distributed on the footbridges.

The tests have been realized to verify and confirm the required conditions of the maximum deflection $w_{\text {lim }}$. The maximum deflection obtained from the full-scale test of the "short" footbridge reached the value $w_{\text {max, test }}=42.4 \mathrm{~mm}$. Next, the deflection obtained from the full-scale test of the "long" footbridge was $w_{\text {max, test }}=55.1 \mathrm{~mm}$. Both the resulting values satisfied the condition for the allowed value of a deflection of temporary footbridge given as $L / 150$, see Table 3 .

Table 3 Values of deflections

\begin{tabular}{|c|c|c|c|c|}
\hline \multirow{3}{*}{ Full-scale tests } & Span & $\begin{array}{c}\text { Actual } \\
\text { deflection }\end{array}$ & $\begin{array}{c}\text { Deflection } \\
\text { limit }\end{array}$ & Utilization \\
\hline & $L$ & $w_{\text {max }, \text { test }}$ & $L / 150$ & \multirow{2}{*}{ [\%] } \\
\hline & {$[\mathrm{mm}]$} & {$[\mathrm{mm}]$} & {$[\mathrm{mm}]$} & \\
\hline "Short" footbr. & 18000 & 42,4 & 120 & 35,3 \\
\hline "Long" footbr. & 36000 & 55,1 & 240 & 23,0 \\
\hline
\end{tabular}

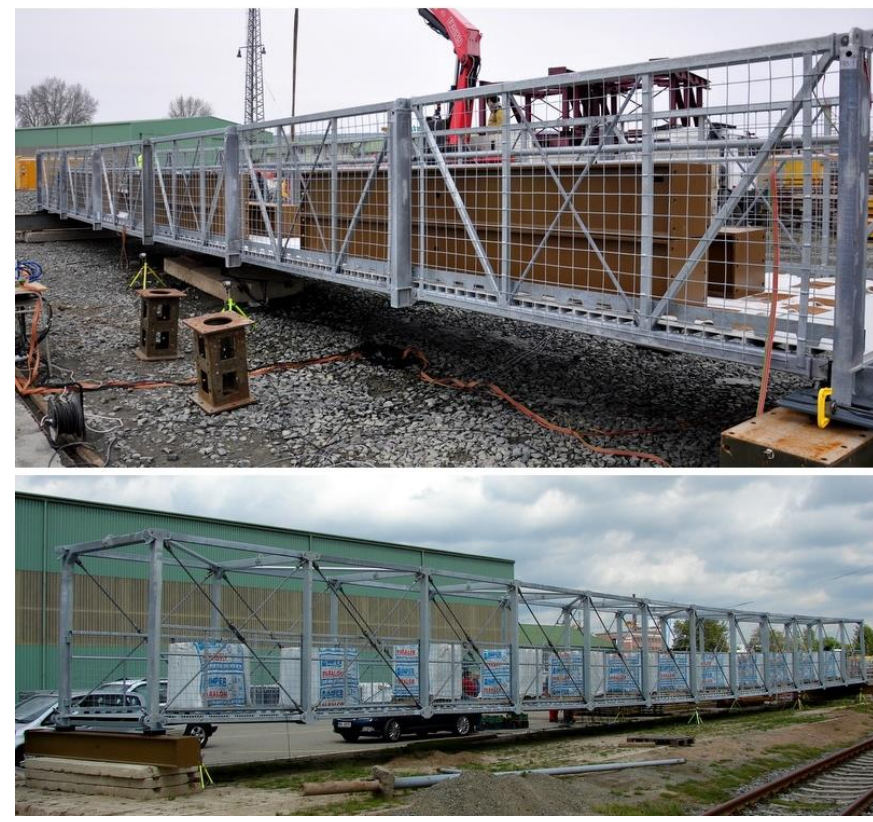

Fig. 5 full-scale testing of the "short" footbridge (on the top) and of the "long" footbridge (on the bottom)

Also all the stress values obtained from the full-scale tests confirmed the assumptions from the previously solved design model (FEM modelling via to Dlubal RFEM Software). The project was successfully finished and a few prototypes of both designed footbridges are already used in practice.

\section{B. Verification of the load-carrying capacity of steel bolts}

Another example concerns steel-concrete structural details, where a large number of load tests have been performed recently on the authors' workplace within the framework of research project oriented to an actual behaviour of steel mechanical post-installed anchors to concrete under various types of load as well as with different material and geometric parameters, see [20] or [21].

As a single specific example, in which the Design assisted by testing method have been used, a part of the research focused on a determination and verification of an ultimate tensile strength $f_{u b}$ of steel anchor bolts can be mentioned, where the tensile load tests have been performed [22] [23].

For this purpose, three groups of specimens have been selected (see Fig.6) with different bolt diameters $d$ and with the bolt grade of 8.8 (i.e. the declared ultimate tensile strength of steel was $800 \mathrm{MPa}$ ). Six specimens in each group have been used (18 specimens in total).

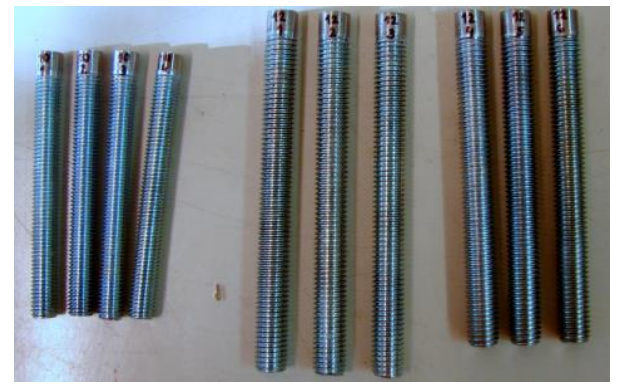

Fig. 6 some prepared specimens for the load tests 
In the first group the bolts with the diameter M12 were used. In the second group the diameter was M10, and finally, in the third group it was the diameter M12.

Results of performed load tests are written in Table 4. In the table $F_{\text {max, test }}$ is a maximum value of tensile loading force in the moment of a failure of a specimen and $f_{u b, t e s t}$ is a value of an ultimate tensile strength of steel based on the declared tensile stress area of the anchor bolt $A_{s}$, which is given as follows: $A_{s}=36.6 \mathrm{~mm}^{2}$ for bolts with the diameter M8, $A_{s}=58 \mathrm{~mm}^{2}$ for bolts with the diameter M10 and finally $A_{s}=84.3 \mathrm{~mm}^{2}$ for the diameter of bolts M12.

Table 4 Test results of all groups of specimens

\begin{tabular}{|c|c|c|c|c|c|c|c|}
\hline \multirow{2}{*}{ 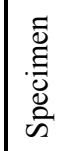 } & $d$ & $F_{\text {max, test }}$ & $f_{u b, t e s t}$ & \multirow{2}{*}{ 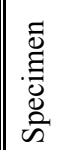 } & $d$ & $F_{\text {max, test }}$ & $f_{u b, t e s t}$ \\
\hline & {$[\mathrm{mm}]$} & {$[\mathrm{kN}]$} & [MPa] & & {$[\mathrm{mm}]$} & {$[\mathrm{kN}]$} & {$[\mathrm{MPa}]$} \\
\hline 1 & M8 & 32,3 & 882,5 & 10 & M10 & 52,3 & 901,7 \\
\hline 2 & M8 & 32,8 & 896,2 & \begin{tabular}{|l|}
11 \\
\end{tabular} & M10 & 58,7 & 1012,1 \\
\hline 3 & M8 & 30,4 & 830,6 & \begin{tabular}{|l|}
12 \\
\end{tabular} & M10 & 52,7 & 908,6 \\
\hline 4 & M8 & 32,2 & 879,8 & \begin{tabular}{|l|}
13 \\
\end{tabular} & M12 & 74,7 & 886,1 \\
\hline 5 & M8 & 30,6 & 836,1 & 14 & M12 & 74,5 & 883,7 \\
\hline 6 & M8 & 32,9 & 898,9 & 15 & M12 & 75,0 & 889,7 \\
\hline 7 & M10 & 52,0 & 896,6 & 16 & M12 & 76,5 & 907,5 \\
\hline 8 & M10 & 48,6 & 837,9 & 17 & M12 & 77,0 & 913,4 \\
\hline 9 & M10 & 50,5 & 870,7 & 18 & M12 & 73,5 & 871,9 \\
\hline
\end{tabular}

Based on the results of all 18 tested specimens, the mean value of the ultimate tensile strength of steel have been determined as $f_{u b, m}=889,1 \mathrm{MPa}$. Next, by using the procedure of the Design assisted by testing method, also the characteristic value $f_{u b, \mathrm{k}}$ and the design value $f_{u b, \mathrm{~d}}$ of the tensile strength of the anchor bolt have been calculated, see Table 5 .

Table 5 Determination of the ultimate tensile strength of the anchor bolt (based on the " $V_{X}$ known" and on the Normal distribution of the variables)

\begin{tabular}{|c|c|c|c|c|}
\hline $\begin{array}{c}f_{u b, m} \\
{[\mathrm{MPa}]}\end{array}$ & $\begin{array}{c}V_{X} \\
{[-]}\end{array}$ & $\begin{array}{c}f_{u b, \mathrm{k}} \\
{[\mathrm{MPa}]}\end{array}$ & $\begin{array}{c}\gamma_{m} \\
{[-]}\end{array}$ & $\begin{array}{c}f_{u b, \mathrm{~d}} \\
{[\mathrm{MPa}]}\end{array}$ \\
\hline 889,11 & 0,05 & 814,07 & 1,00 & 814,07 \\
\hline
\end{tabular}

As visible in of Table 5 description, the normal distribution of variables have been considered during the characteristic value determination and " $V_{X}$ known" option have been used in case of a variation coefficient. Specifically, the value $V_{X}=0,05$ have been taken. This relatively very small value is based on a large number of previously performed static tension tests (over 100 tests) of mechanical expansion anchors.

Then, based on the relevant standard Eurocode 3 [24] for steel structures, the partial factor $\gamma_{m}$ have been taken $\gamma_{m}=1.0$ (this value can be considered thanks to the high reliability of the construction steel). Hence, the design value of the bolt tensile strength have been determined as $f_{u b, \mathrm{~d}}=814,0 \mathrm{MPa}$.

The illustration of the used test arrangement together with one example of failed specimen can be seen in Fig. 7.

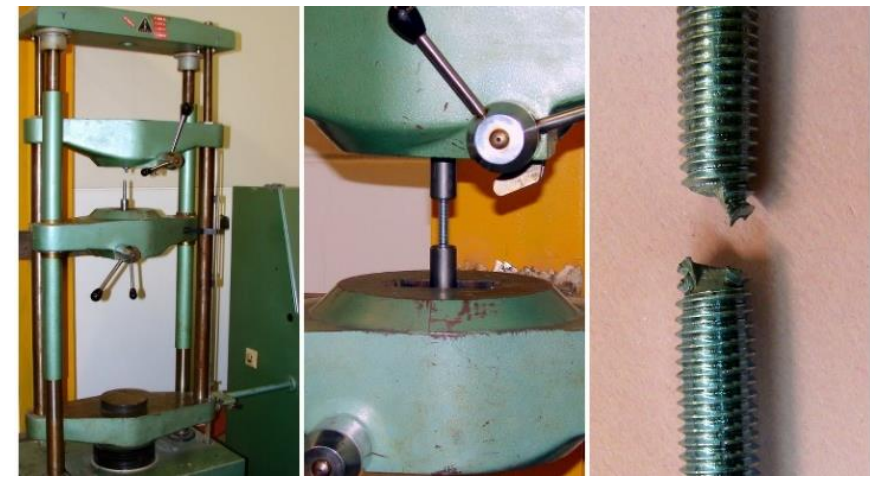

Fig. 7 illustration of load tensile tests arrangement and an example of a failed specimen

Next, for an illustration and comparison with different possible options, other values of the design tensile strength are written in Table 6 and shown in a graph on Fig. 8 (they are determined also according the " $V_{X}$ unknown" option and with an assumption of a log-normal distribution of variables, too). The procedures how to get all the values are described in chapter II (see above).

Table 6 Comparison of the influence of different options in case of using the Design assisted by testing method

\begin{tabular}{|c|c|c|c|}
\hline \multicolumn{2}{|c|}{$V_{X}$ known $\rightarrow V_{X}=0,05$} & $\begin{array}{c}\text { Determination } \\
\text { of the design } \\
\text { value with the } \\
\text { help of the } \\
\text { characteristic } \\
\text { value and } \\
\text { factor } \gamma_{m}\end{array}$ & $\begin{array}{c}\text { Direct } \\
\text { determination } \\
\text { of the design } \\
\text { value }\end{array}$ \\
$\begin{array}{c}\text { (declared value of strength } \\
\left.f_{u b}=800 \mathrm{MPa}\right)\end{array}$ & $\begin{array}{c}f_{u b, \mathrm{~d}} \\
{[\mathrm{MPa}]}\end{array}$ & $\begin{array}{c}f_{u b, \mathrm{~d}} \\
{[\mathrm{MPa}]}\end{array}$ \\
\hline Distribution & $V_{X}$ & 814,07 & 748,00 \\
\hline Normal & $V_{X}$ known & 729,78 & 550,00 \\
\cline { 2 - 4 } & $V_{X}$ unknown & 816,46 & 758,03 \\
\hline Log-normal & $V_{X}$ known & 822,06 & 753,22 \\
\cline { 2 - 4 } & $V_{X}$ unknown & 826 &
\end{tabular}

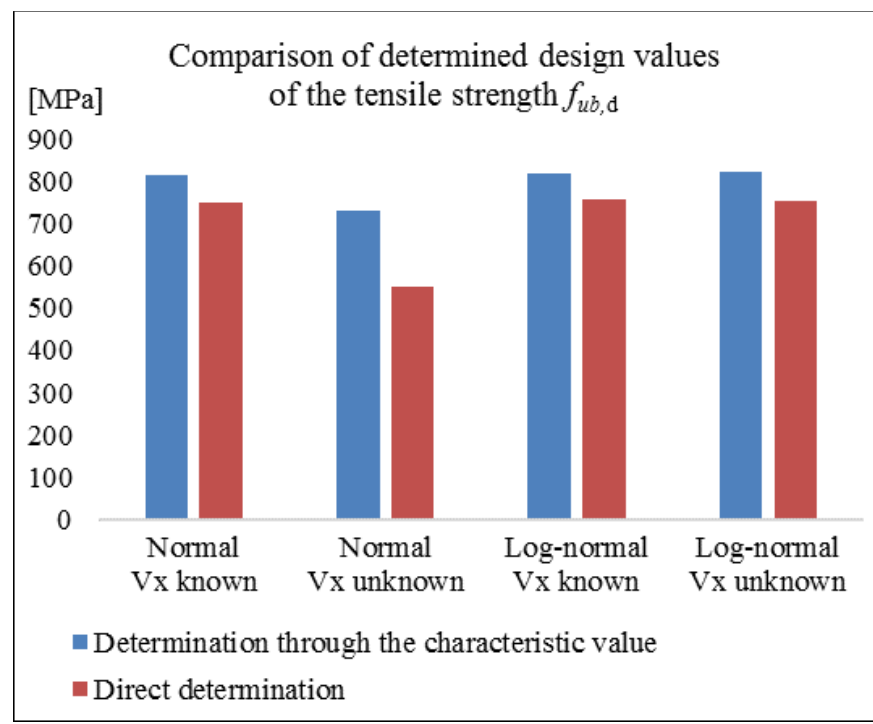

Fig. 8 comparison of determined values of tensile strength 
To understand the influence of chosen value of the variation coefficient $V_{X}$ on a determination of the design value, the graph is drawn (see Fig. 9). In this graph different values of assumed " $V_{X}$ known" were chosen (from 0.01 to 0.25 ) together with their corresponding result values of the design tensile strength. These values can be in this graph also compared to the design values in case of the option " $V_{X}$ unknown", which is, for each case a constant value (red the line in the graph).

This comparison is created only for the case with a normal distribution and for the procedure, where design values are determined based on a characteristic values. It would be also possible to make similar graphs for the other possible cases.

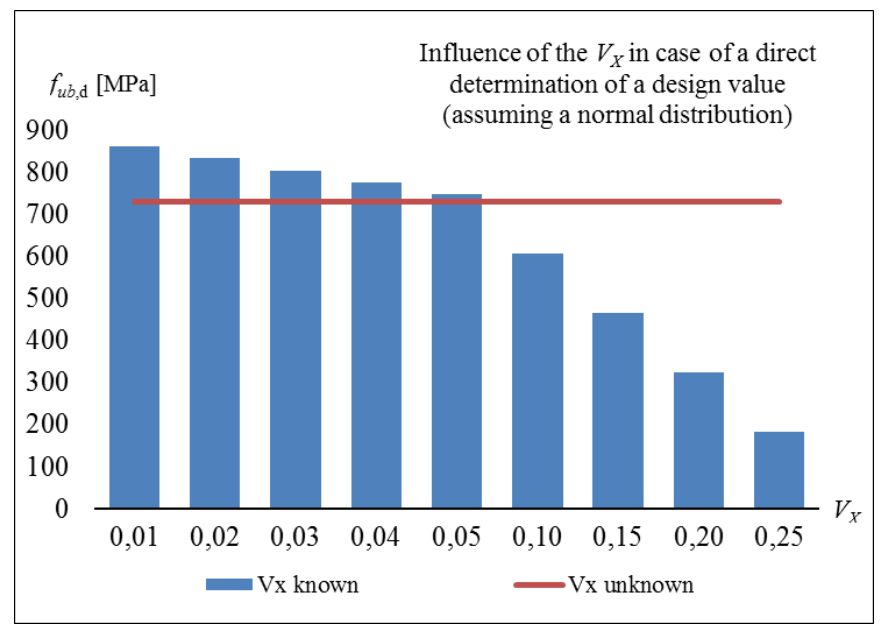

Fig. 9 influence of the knowledge of the variation coefficient $V_{X}$

It is obvious, that the influence of $V_{X}$ can be very high. In each case, it can be found a specific limit value of $V_{X}$, where its accuracy has still the advantageous influence on the design value. From this limit, the option $V_{X}$ unknown could be even better to use for the determination of the design value.

However, in each case it has to be decided the more accurate solution according to all the boundary conditions and all the input parameters in each specific case.

\section{Loading tests of bonded connections of GFRP members} subjected to the shear force

As the last example of the Design assisted by testing method and its combination with performed experiments, the loading tests of adhesively bonded connections of members made of GFRP $($ GFRP $=$ Glass-Fiber Reinforced Plastic) have been selected for this article. Specifically, the tests were designed to obtain characteristic and design values of a shear resistance of this kind of connection with using of different geometric parameters [25] [26]. The results of these tests have been primarily intended to verify the actual behavior and the loadbearing capacity of these joints in the case of static shear loading for the subsequently prepared tests with cyclic loading and also for the validation of FEM models.

The load tests with the static shear force have been realized as one part of the research project, which was generally focused on design of construction details made of GFRP members.
Note: Structure members made of GFRP are recently very often used in the field of civil and bridge engineering (for example for façade systems, bridge barriers, bridge decks, fittings, etc.). As their advantage, a quite high load-carrying capacity in combination with a relatively low self-weight can be considered [27]-[29]. However, this structural material is usually quite expensive, too.

As mentioned above, the experiments have been focused on the shear load tests of bonded connections and on their static (monotonic) load-carrying capacity determination. For this purpose, five series of specimens have been selected for testing (99 specimens in total), where all the series had a very similar geometric configuration of specimens, which have been designed as double-lap joints with two cower adherents and one middle adherent between them, see Fig. 10 (the singlelap joint have not been considered, because of the effect of non-symmetric configuration [30] [31] [32].

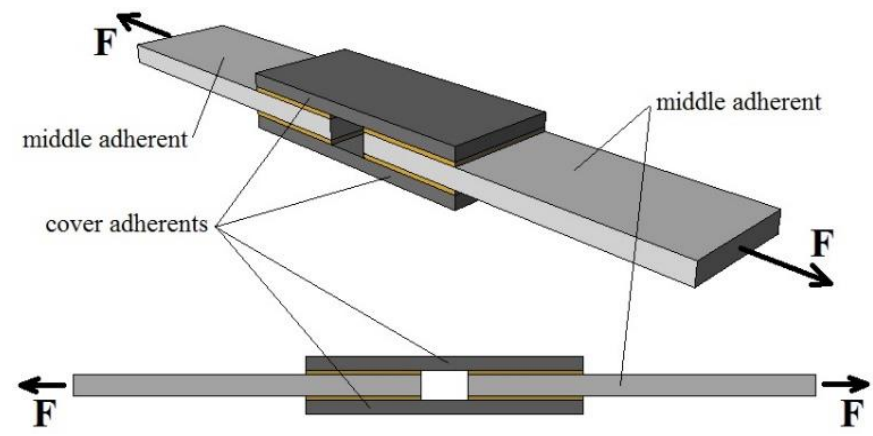

Fig. 10 scheme of the designed GFRP double-lap bonded joints of composite-to-composite type

In each series some specific geometric parameters have been selected, to get information about their possible influence (for example a different width, different thickness of an adherent, the different length of an overlapping, etc.). In one series (series S4) also the modified geometric shape of the cover adherents have been designed by using the skewed edges (see Fig. 11 and Fig. 12) to find out if this configuration can have an effect on the shear resistance of the bonded joint [33].

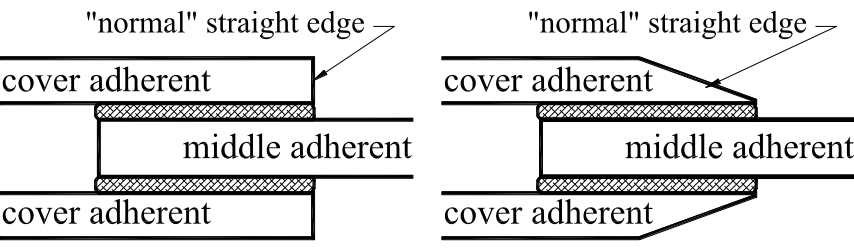

Fig. 11 configuration of the cover adherent

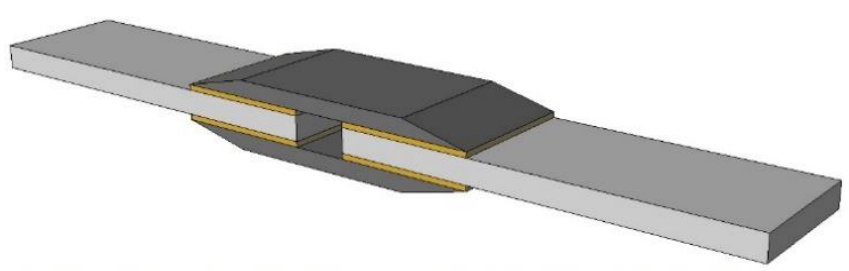

Fig. 12 scheme of the joint with the skewed edges of cover adherents 
Next, Fig. 13 shows the used specimens as well as of the load test arrangement. During the tests, a tensile force $F$ have been applied in the longitudinal direction of the connection (this loading force actually caused a shear stress in the joint).
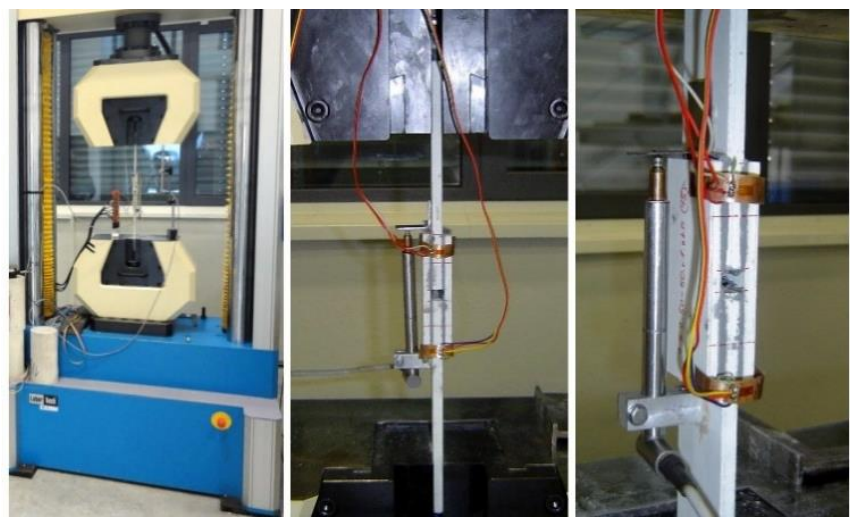

Fig. 13 load test arrangement of GFRP bonded joints

Based on the elaboration of all 99 realized load tests, the force-to-deflection and shear stress-to-relative displacement relationships have been subsequently evaluated. Then, the mean values of the shear force $F_{\text {mean,test }}$ and of the shear stress $\tau_{\text {mean,test }}$ for each series have been calculated together with the values of the relevant variation coefficient $V_{X}$. Next, by using the Design assisted by testing method the characteristic $\left(\tau_{u l t, \mathrm{k}}\right)$ and design $\left(\tau_{u l t, \mathrm{~d}}\right)$ values of the shear stress resistance have been determined. Also numerical (FEM) models have been created (using the Dlubal RFEM software) for the comparison with loading test results. All the obtained values are clearly arranged in Table 7. The results of the shear resistance are shown in Fig. 14.

Table 7 Results of all 5 test series

\begin{tabular}{|l|c|c|c|c|c|}
\hline \multicolumn{1}{|c|}{ Test series } & S1 & S2 & S3 & S4 & S5 \\
\hline$F_{\text {mean,test }}[\mathrm{kN}]$ & 29,77 & 32,48 & 14,70 & 16,21 & 40,31 \\
\hline$V_{X}[-]$ & 0,084 & 0,089 & 0,125 & 0,126 & 0,139 \\
\hline$\tau_{\text {mean, }, \text { test }}[\mathrm{MPa}]$ & 5,98 & 6,57 & 5,96 & 6,57 & 4,06 \\
\hline$V_{X}[-]$ & 0,084 & 0,087 & 0,113 & 0,125 & 0,142 \\
\hline$\tau_{\text {ult } \mathrm{k},}[\mathrm{MPa}]$ & 4,85 & 5,33 & 4,77 & 5,13 & 3,00 \\
\hline$\tau_{\text {ult, } \mathrm{d}}[\mathrm{MPa}]$ & 3,39 & 3,72 & 3,52 & 3,59 & 1,70 \\
\hline$\tau_{\text {ult }, \text { FEM }}[\mathrm{MPa}]$ & 4,72 & 6,45 & 4,72 & 5,87 & 2,65 \\
\hline
\end{tabular}

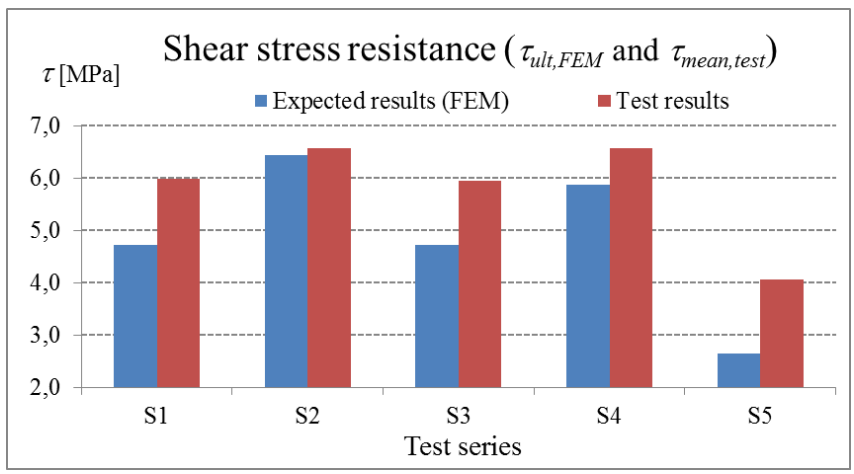

Fig. 14 comparison of the shear resistances for the values obtained from the test results and the values from the FEM models
It can be seen, that the values of FEM models and the mean values of shear stress obtained from the loading tests are very similar (actually, in each case, the actual values are always slightly higher).

In addition to the values described above, the failure modes specified in the standard ASTM [34] have also been observed and recorded in order to obtain a better understanding of the actual behaviour of this type of connection.

According this standard, seven modes of failure are defined (in dependence on a position of a GFRP matrix separation) as follows:

- The "Adhesive Failure" is defined as a rupture of the bonded joint directly at the adherent-to-adhesive interface (i.e. the failure of the contact between the adhesive and the member).

- The "Cohesive Failure" is a pure failure of the adhesive itself (the separation occurs only within the adhesive, no matrix of the GFRP member is visible).

- The "Thin-Layer Cohesive Failure" (TLCF) is very similar to the previous "Cohesive Failure". However, in this case, the failure appears very close to the interface of adherent-toadhesive.

- In the "Fiber-Tear Failure" (FTF), which is the rupture of the GFRP member itself, the failure occurs on both surfaces (the GFRP matrix is visible, i.e. reinforcing glass fibres appears).

- Next, the "Light-Fiber-Tear Failure" (LFTF) is similar to the previous one. However, the GFRP matrix is visible only as a very thin layer (only a few or even no reinforced glass fibres are transferred between the adhesive and the member)

- The "Stock-Break Failure" is characterized by the full rupture of the GFRP member outside the area of the connection itself.

- In the "Mixed Failure" two or more of previously defined failures are combined.

Fig. 15 shows three examples of failed specimens and for a better understanding of the described failure modes above, a simplified illustration of all of them is shown in Fig. 16.

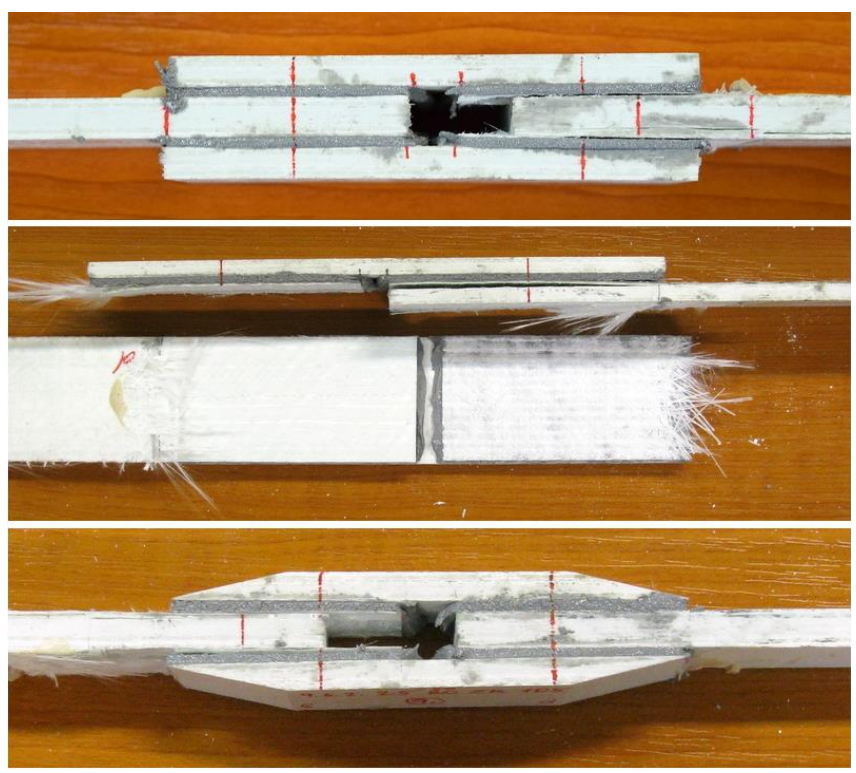

Fig. 15 failed specimens (an example of the specimen with skewed edges of the cover adherents is on the bottom) 
$F$

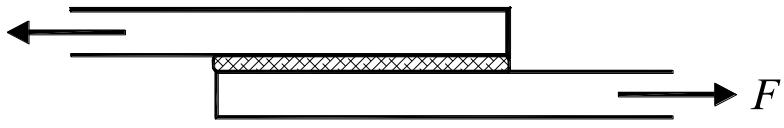

(a)

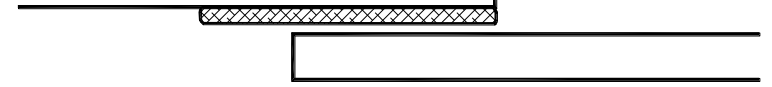

(b)

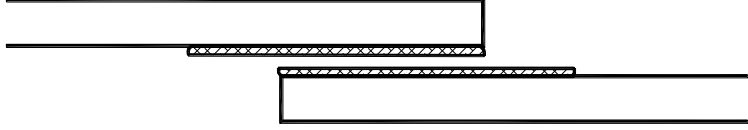

(c)

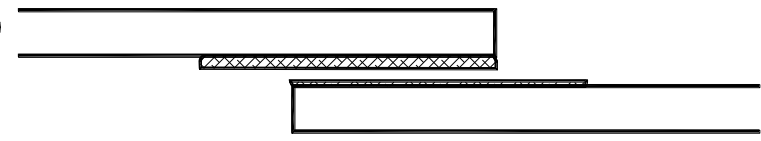

(d)
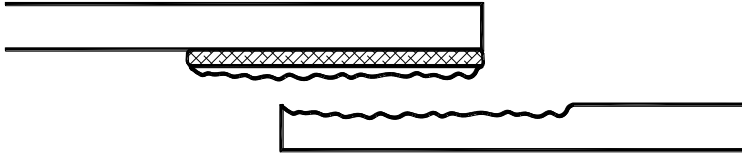

(e)

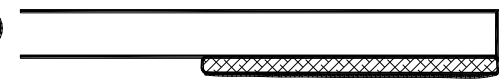

(f)

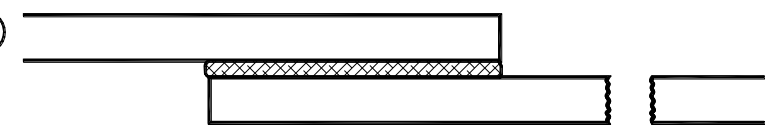

Fig. 16 illustration of the general described failure modes of the bonded connections made of GFRP members: $\mathrm{a}=$ Adhesive failure, $\mathrm{b}=$ Cohesive Failure, $\mathrm{c}=\mathrm{TLCF}, \mathrm{d}=\mathrm{FTF}, \mathrm{e}=\mathrm{LFTF}$,

$\mathrm{f}=$ Stock-Break Failure (the meaning of the abbreviations used is explained above in the description of the failure modes)

All 99 performed experiments were designed to obtain static load-bearing capacity and to verify the actual behaviour of the designed joints under static shear loading.

Based on these results, it is planned to perform further tests, this time with cyclic stress, as the effort is to use the joint also for bridge structures, where it is important to consider repeated (fatigue) loading. Research in the case of cyclic loading is currently being carried out and its results will be presented in another paper.

Tests of similar adhesively bonded joints with added bolts are also planned for the future to obtain their load-carrying capacity compare to the basic bonded connections [35].

The resulting values are also continuously used for the validation of numerical models, which are intended to extend the theoretical tests with the possibility of changing the design parameters.

\section{CONCLUSION}

The philosophy and procedures of the Design assisted by testing approach are described in detail in chapter II. Then, particular conclusions and results of several selected individual load tests are written in chapter III in case of design of specific construction elements (members) and details.
It can be said, that the Design assisted by testing method is very useful way for obtaining characteristic and design values in various cases of a construction design (for various used materials, different types of loading forces, stresses, etc.), especially if, for that constructions, materials or elements do not exist any specific standards. However, the results cannot be generalized, because they are always very strongly connected to each specific case. Also, in some cases, it is not very easy to achieve a large number of tests in order to obtain more accurate results. The way how to increase the number of results can be the use of numerical models, which are based on the test results.

The evaluation of the design values strongly depends not only the number of tests (or specimens) but also on the knowledge about variation coefficient (as described in Part B of chapter III).

Therefore, it is always very important to choose some suitable arrangement of load tests, which in combination with the use of the Design assisted by testing approach would lead to obtaining relevant results.

Note: The research project focused on the design of steel temporary footbridges (described in Part "A" of Chapter III) has been successfully finished. Its result is real prototypes of steel truss footbridges, which are already used by some companies in the Czech Republic. In the near future, a new cooperation with manufacturers and developers of bridge structures is planned, as well as the design of new types of temporary bridge structures for road and rail transportation. This time it is planned to use not only steel, but some other materials, too. After the obtained experiences with GFRP members, also the possibility of using this material for the temporary constructions will be considered [36].

\section{APPENDIX}

All presented experiments (and their results) in this paper were performed and achieved on the authors' workplace.

\section{ACKNOWLEDGMENT}

M. Štrba, M. Karmazínová and P. Bukovská thank to the project no. FAST-S-20-6400 "The analysis, experimental verification and possibilities of the interaction of materials effective utilization in case of composite structural members" (the "specific research project" of the Brno University of Technology, Czech Republic) supported by Ministry of Education, Youth and Sports in the Czech Republic.

\section{REFERENCES}

[1] EN 1990 Eurocode: Basis of Structural Design, The Annex D: Design assisted by testing, CEN Brussels, 2004.

[2] M. Holický, J. Marková, Basis of building structures design: Handbook for CSN EN 1990 (original is in the Czech language), CKAIT, 2007. ISBN 978-80-87093-27-6.

[3] M. Karmazínová, J. Melcher and Z. Kala, "To applications of methods of design assisted by testing", In Proceedings of the 5th European Conference EUROSTEEL 2008 (held in Graz), Belgium, ECCS, 2008, pp. 803-808. ISBN 92-0147-000-90.

[4] M. Karmazínová, "Structural members design resistance based on the methods using the design assisted by testing philosophy", In Proceedings of the 10th International Conference "Modern Building 
Materials, Structures and Techniques", VGTU Vilnius, 2010, pp. 667674. ISBN 978-9955-28-593-9.

[5] M. Karmazínová, J. Melcher, "Methods of the design assisted by testing - applicable tools for the design resistance evaluation using test results", In Proceedings of the 2nd International Conference on Mathematical Models for Engineering Science (MMES'11) Mathematical Models and Methods in Modern Science", Institute of Environment, Engineering, Economics and Applied Mathematics, WSEAS Press, Puerto de la Cruz, 2011, pp. 31-36. ISBN 978-1-61804-055-8.

[6] M. Karmazínová, M. Pilgr, J. Melcher, "Methods based on the approach of the design assisted by testing applied to the determination of material properties, In Proceedings of the 2nd International Conference on Mathematical Models for Engineering Science (MMES'11) Mathematical Models and Methods in Modern Science", Institute of Environment, Engineering, Economics and Applied Mathematics, WSEAS Press, Puerto de la Cruz, 2011, pp. 25-30. ISBN 978-1-61804055-8.

[7] M. Karmazínová, J. Melcher, "Design assisted by testing applied to the determination of the design resistance of steel-concrete composite columns", In Proceedings of the 13th WSEAS International Conference on Mathematical and Computational Methods in Science and Engineering MACMESE '11', WSEAS Press, Catania, 2011, pp. 420425. ISBN 978-1-61804-046-6.

[8] M. Karmazínová, "Design assisted by testing - a powerful tool for the evaluation of material properties and design resistances from test results", International Journal of Mathematical Models and Methods in Applied Sciences, 2012, pp. 376-385. ISSN 1998- 0140.

[9] ISO 2394 General principles on reliability for structures, ISO, 2015.

[10] ISO 12491 Statistical methods for quality control of building materials and components, ISO, 1997.

[11] G. Augusti, A. Barratta, F. Casciati, Probabilistic methods in structural engineering, Chapman and Hall, London, 1984. ISBN 0-412-22230-2.

[12] W. Lin, T. Yoda, Bridge Engineering - Classifications, Design Loading, and Analysis Methods, Butterworth-Heinemann, 2017. ISBN 978-0-12804432-2.

[13] A. Boracchini, Design and Analysis of Connections in Steel Structures: Fundamentals and Examples, Strauss GmbH, Mörlenbach, 2018. ISBN: 978-3-433-03122-3.

[14] J. Bujňák, P. Bujňáková, Bridges - Concept and design (original in Slovak language), University of Žilina, 2020, ISBN 978-80-5541634-2.

[15] M. Strba, "On the problems of testing methodology used in case of the temporary steel through truss footbridge development", International Journal of Mechanics, North Atlantic University Union, U.S.A., Issue 2, Vol. 7, 2013, pp. 73-80. ISSN 1998-4448.

[16] M. Štrba, M. Karmazínová, "The development and testing of a new type of the temporary steel truss footbridge with closed cross-section", International Journal of Mechanics, North Atlantic University Union, U.S.A., Vol. 9, 2015, pp. 173-180. ISSN 1998-4448.

[17] M. Karmazínová, J. Melcher, M. Pilgr, M. Štrba, Full-scale tests of temporary steel (foot)bridges, Recent Advances in Mechanics and Materials in Design, University of Porto, Portugal, 2015, pp. 305-317. ISBN 978-989-98832-2-2.

[18] EN 1993-1-9 Eurocode 3: Design of steel structures - Part 1-9: Fatigue, CEN Brussels, 2005.

[19] M. Karmazínová, P. Simon, "Fatigue Tests of Assembly Joints of Truss Main Girders of Newly Developed Temporary Footbridges", International Journal of Mechanics, North Atlantic University Union, U.S.A., Vol. 7, 2013, pp. 475-483. ISSN 1998-4448.

[20] M. Štrba, M. Karmazínová, Using of the design assisted by testing method in case of the experimental verification of the load-carrying capacity of expansion anchors, International Journal of Mechanics, North Atlantic University Union, U.S.A., Vol. 10, 2016, pp. 227-234. ISSN 1998-4448.

[21] M. Štrba, M. Karmazínová, V. Václavíková, The influence of material and geometric parameters on the design of steel mechanical anchors to concrete under tension loading, International Journal of Mechanics, North Atlantic University Union, U.S.A., Vol. 12, 2018, pp. 131-139. ISSN 1998-4448.

[22] M. Štrba, M. Karmazínová, "On the problems of actual behaviour and load-carrying capacity of steel anchor bolts subjected to repeated tension loading", In Proceedings of 3rd European Conference of Civil Engineering (ECCIE '12) "Recent Advances in Engineering", WSEAS Press, Paris, France, 2012, pp. 273-276. ISSN 1877-7058, ISBN 978-161804-137-1.
[23] M. Štrba, Steel expansion anchors under cyclic tensile loading (original in the Czech language), PhD Thesis, vol. 633, Brno, 2011. ISSN 12134198.

[24] EN 1993-1-1 Eurocode 3: Design of steel structures - Part 1-1: General rules and rules for buildings, CEN Brussels, 2016.

[25] M. Štrba, M. Karmazínová, Loading tests of adhesively bonded joints of glass-fiber reinforced plastic composite members, International Journal of Theoretical and Applied Mechanics, IARAS (International Association of Research and Science), Vol. 1, 2016, pp. 299-302. ISSN 2367-8992.

[26] M. Štrba, M. Karmazínová, Experimental Verification of the Shear Load-Carrying Capacity of Adhesively Bonded Joints, WSEAS Transactions On Applied And Theoretical Mechanics, World Scientific and Engineering Academy and Society, Vol. 12, 2017, pp. 11-16. ISSN 1991-8747.

[27] F. Ascione, Mechanical behaviour of FRP adhesive joints, Composites, Part B: Engineering, Vol. 40, Elsevier Ltd., 2009, pp. 116-124, ISSN 1359-8368.

[28] F. Ascione, Ultimate behaviour of adhesively bonded FRP lap joints, Composites, Part B: Engineering, Vol. 40, Elsevier Ltd., 2009, pp. 107115. ISSN 1359-8368.

[29] A. T. Abdelaziz, R. Boukhili, S. Achiou, S. Gordon, H. Boukehili, Bonded joints with composite adherents, Part I, Effect of specimen configuration, adhesive thickness, spew fillet and adherent stiffness on fracture, International Journal of Adhesion \& Adhesives, Vol. 26, 2006, pp. 226-236. ISSN 0143-7496.

[30] T. Keller, T. Vallee, Adhesively bonded lap joints from pultruded GFRP profiles. Part I: Stress-strain analysis and failure modes, Composites, Part B: Engineering. Vol. 36, Issue 4, Elsevier Ltd., 2005; pp. 331-340. ISSN $1359-8368$

[31] T. Keller, T. Vallee, Adhesively bonded lap joints from pultruded GFRP profiles. Part II: joint strength prediction. Composites, Part B: Engineering. Vol. 36, Issue 4, Elsevier Ltd., 2005; pp. 341-350. ISSN 1359-8368.

[32] P. Simon, Joints from FRP composite intended for transport, Ph.D Thesis, Brno University of Technology, 2018.

[33] D. V. Srinivasan, V. Ravichandran, S. Idapalapati, Failure analysis of GFRP single lap joints tailored with a combination of tough epoxy and hyperelastic adhesives, Composites Part B: Engineering, Elsevier Ltd., vol. 200, 2020. ISSN: 1359-8368.

[34] STM D5573-99 Standard Practice for Classifying Failure Modes in Fiber Reinforced Plastic (FRP) Joints, ASTM, West Conshohocken, PA, 2012.

[35] J. Qureshi, Y. Nadir, S. K. John, Bolted and bonded FRP beam-column joints with semi-rigid end conditions, Composite Structures, vol. 247, Elsevier Ltd., 2020. ISSN: 0263-8223.

[36] A. Muc, A. Stawiarski, M. Chwał, Design of the hybrid FRP/concrete structures for bridge constructions, Composite Structures, vol. 247, Elsevier Ltd., 2020. ISSN: 0263-8223.

M. Štrba (M'17) is a civil engineering professional with vast academic experience, currently he is an assistant professor at Institute of Metal and Timber Structures, Faculty of Civil Engineering at Brno University of Technology in the Czech Republic. He graduated in civil engineering in the year of 2002 from Brno University of Technology and in 2011 he got Civil engineering Doctors' degree (Ph.D.) at the same university with the thesis "Steel expansion anchors under cyclic tensile loading" focused on an experimental research in the field of behaviour and ultimate capacity determination in case of very often used type of anchorage elements, steel mechanical expansion anchors to concrete, exposed to cyclic tensile loading. $\mathrm{He}$ has published more than 60 papers so far and participated in many European and international conferences focused on the civil engineering and on the design of buildings and constructions, especially steel and composite steel-concrete structures and bridges. His main specialization is the design of steel construction, composite steel-concrete structures, the use of highstrength materials (like HSS or/and HPC) and recently the use of composite GFRP members for the bearing structures, too.

\section{Creative Commons Attribution License 4.0 (Attribution 4.0 International, CC BY 4.0)}

This article is published under the terms of the Creative Commons Attribution License 4.0 https://creativecommons.org/licenses/by/4.0/deed.en_US 